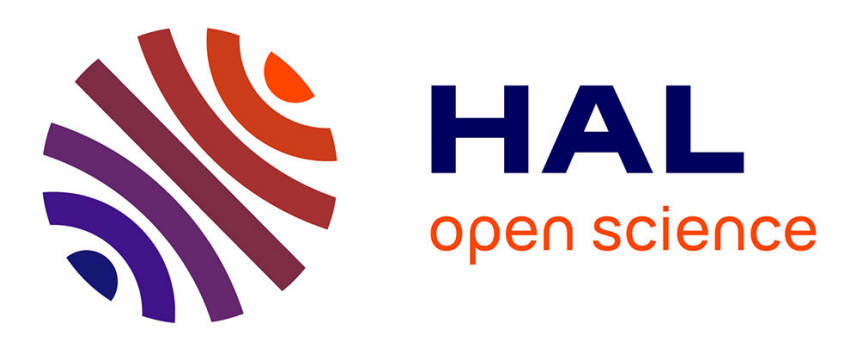

\title{
Chemical properties of wood are under stronger genetic control than growth traits in Populus tomentosa Carr.
} Pingdong Zhang, Feng Wu, Xiangyang Kang

\section{To cite this version:}

Pingdong Zhang, Feng Wu, Xiangyang Kang. Chemical properties of wood are under stronger genetic control than growth traits in Populus tomentosa Carr.. Annals of Forest Science, 2015, 72 (1), pp.8997. 10.1007/s13595-014-0401-5 . hal-01284156

\section{HAL Id: hal-01284156 https://hal.science/hal-01284156}

Submitted on 7 Mar 2016

HAL is a multi-disciplinary open access archive for the deposit and dissemination of scientific research documents, whether they are published or not. The documents may come from teaching and research institutions in France or abroad, or from public or private research centers.
L'archive ouverte pluridisciplinaire HAL, est destinée au dépôt et à la diffusion de documents scientifiques de niveau recherche, publiés ou non, émanant des établissements d'enseignement et de recherche français ou étrangers, des laboratoires publics ou privés. 


\title{
Chemical properties of wood are under stronger genetic control than growth traits in Populus tomentosa Carr.
}

\author{
Pingdong Zhang $\cdot$ Feng Wu $\cdot$ Xiangyang Kang
}

Received: 16 December 2013 / Accepted: 23 June 2014 / Published online: 4 July 2014

(C) INRA and Springer-Verlag France 2014

\begin{abstract}
- Context The genetic development of some wood quality characteristics in early stage is particularly attractive since these properties are generally inherited. A clear understanding of the genetic control of chemical properties of wood (extractives, holocellulose, and lignin content) and growth traits (tree height, diameter at breast height, and stem volume) of corewood is a prerequisite for breeding for higher wood quality in triploid hybrid clones of Populus tomentosa.

- Aims The experiments aimed at unraveling genetic effect and clone $\times$ site interactions on chemical properties of wood and growth traits of corewood derived from triploid hybrid clones of $P$. tomentosa.

- Methods Four 5-year-old clonal trials established in northern China were used to determine the clonal variations and clone $\times$ site interactions of chemical properties of wood and growth traits. Two hundred sixteen trees from nine clones were sampled in the four sites.
\end{abstract}

Handling Editor: Bruno Fady

Contribution of the co-authors Pingdong Zhang was responsible for planning and building the clonal trails, collecting wood discs sample and tree growth measurements, generating the phenotypic data set, analyzing the results, and writing the paper. Feng Wu was responsible for collecting wood discs sample and wood chemical properties measurements. Xiangyang Kang was responsible for planning and guiding this research.

Key message The genetic development of wood properties of corewood is attractive. Two hundred sixteen trees from nine triploid clones were sampled at four clonal trials. The tests and genetic analyses revealed that chemical properties of wood were under stronger genetic control than growth traits.

P. Zhang $(\bowtie) \cdot F$. Wu $\cdot$ X. Kang

National Engineering Laboratory for Tree Breeding, Key laboratory of Genetics and Breeding in Forest Trees and Ornamental Plants, Ministry of Education, Beijing Forestry University, No.35, Qinghua East Road, Haidian District, 100083 Beijing, People's Republic of China

e-mail: zhangpd@bjfu.edu.cn
- Results Site had a highly significant $(P<0.001)$ effect on extractives and tree growth and a moderate effect on lignin and holocellulose. Clonal effects were also significant $(P<0.05)$ for all studied traits. Clone $\times$ site interactions were significant for all studied traits except for holocellulose. No significant estimated correlations between chemical properties of wood and growth traits were observed. However, a weak and negative estimated correlation between lignin and growth traits existed. This suggests that selection for growth traits might lead to a minor reduction in lignin in triploid breeding of $P$. tomentosa.

- Conclusions Our results revealed that chemical properties of wood were under stronger genetic control than growth traits in triploid hybrid clones of $P$. tomentos $a$. Therefore, breeding programs might be able to improve these chemical properties of wood and growth traits in these hybrids.

Keywords Chemical properties of wood - Genetic variation . Genetic correlation · Populus tomentosa - Growth traits . Triploid hybrid clones

\section{Introduction}

Chinese white poplar, Populus tomentosa Carr. (section Populus, family Salicaceae, genus Populus), is a native timber species to China. As an important and fast growing tree of good quality, it is widely used for landscape cultivation, ecological protection, and the production of timber and pulp. Natural triploid $P$. tomentosa $(2 \mathrm{n}=3 \mathrm{x}=57)$ which was considered to originate a natural $2 \mathrm{n}$ pollen crossing a normal (1n) egg was first discovered in 1992 by Zhu et al. (2006) and described as a tree of larger than normal size with large leaves. The growth rate of the triploid is as approximately two times as that of the diploid, and these trees have longer fibers and improved pulp properties (Yao and Pu 1998). The discovery 
and subsequent evaluations of the triploid $P$. tomentosa attracted the attention of investigators, leading to a search for successful triploid breeding programs using selection, hybridization, and polyploidy techniques (Zhu et al. 1995; Kang et al. 1999, 2000).

Triploid breeding and intensive silviculture of triploid hybrid $P$. tomentosa have increased forest plantation productivity significantly in northern China. With improved growth, rotation ages have been reduced to about 5 to 10 years compared with 10 to 20 years in unimproved stands (Zhu 2006). Therefore, the percent of corewood from plantations has increased mainly because of faster growth and early harvesting. Corewood typically has less desirable wood properties than mature wood, e.g., lower density, shorter fiber length, and higher lignin content. These wood properties are associated with low pulp yield and high pulping costs (Shupe et al. 1996; Sykes et al. 2003).

The genetic development of some wood quality characteristics in early stage is particularly attractive since properties such as wood density, fiber morphology, and elastic modulus are generally inherited (Zobel and van Buijtenen 1989; Pu et al. 2002; Lindström et al. 2004; Naranjo et al. 2012). Furthermore, these properties show moderate genetic ageage correlations between juvenile and mature wood, demonstrating that tree selection could be effective even in relatively young trees and thus may be based on phenotypic selection as well (Hannrup and Ekberg 1998; Hylen 1999). Moreover, some other property traits can be highly correlated; for example, wood density can be used as an indicator of fiber morphology (e.g., fiber length, fiber diameter, and fiber wall thickness) since fiber morphology has a strong effect on density (Zhang et al. 2012).

In China, triploid breeding programs for P. tomentosa have, in general, emphasized improvements in tree growth, trunk formation, disease resistance, and adaptability (Zhu 2006). A few studies have focused on the wood properties of triploid clones of $P$. tomentosa. Variations in wood density among clones, radial direction, and vertical direction were reported by Xing and Zhang (2000). Pu et al. (2002) examined variations in fiber morphology between clones and annual rings, while Wu et al. (2011) studied the genetic parameters of fiber traits. However, these studies were performed on a single site or based on a small number of samples or clones, whereas the present study used the same nine clones studied by $\mathrm{Wu}$ et al. (2013) on each of the four sites. For tree improvement purpose, estimation of quantitative parameters requires that more genotypes than those used in the previous studies be tested and that studies are conducted at different locations. Additionally, it is important to study wood quality traits before incorporating them into tree breeding programs to maximize the economic gains.

Recently, Zhang et al. (2012) reported the genetic variations of tree growth, basic wood density, and fiber length of triploid hybrid clones of $P$. tomentosa at three clonal trials. Based on the same set of triploid hybrid clones, genetic control of fiber properties (fiber length, fiber width, coarseness) and their correlations to growth rate were documented by Zhang et al. (2013). To better understand the genetic control of wood density and fiber properties, estimation of genotypic parameters of these wood properties in triploid hybrid clones of $P$. tomentosa at five clonal trials were showed by $\mathrm{Wu}$ et al. (2013). Within-stem variations in basic wood density and fiber properties of triploid hybrids of P. tomentosa at three clonal trials were analyzed (Wu et al. 2014). However, little has been done to improve chemical properties of wood in triploid hybrid clones of $P$. tomentosa in China.

In this study, we examined chemical properties of wood and growth of nine triploid clones of $P$. tomentosa in northern China. The objective of our study was threefold: to (1) compare genetic variation in primary growth traits, extractive content, holocellulose content, and lignin content on four field test sites; (2) examine genotype by environment interaction of the same traits; and (3) study relationships between growth traits and chemical properties of wood.

\section{Materials and methods}

\subsection{Material and data collection}

The materials used in this study were based on four triploid hybrid poplar clonal trials in northern China, which were established with cuttings by Beijing Forestry University on agricultural soil. Characteristics of the four clonal trials are described by Wu et al. (2013) and presented in Table 1. The planted cuttings were $20-25 \mathrm{~cm}$ in length and $1.5-2.0 \mathrm{~cm}$ in diameter. There were three replicates in the nursery. Clonal trials were established in a randomized block design with three blocks. The trials consisted of nine triploid hybrid clones on each site (Table 2). The nine triploid hybrid clones were induced from a crossing between a $2 \mathrm{n}$ pollen producer of diploid P. tomentosa and a diploid hybrid P. tomentosa $\times$ Populus bolleana L. (Zhu et al. 1995) or a diploid hybrid Populus alba L. $\times$ Populus glandulosa Uyeki (Zhu 2006). Seven of them came from the first hybrid combination, while the $P$. tomentosa $\times P$. bolleana parents were produced by $\mathrm{Xu}$ in 1958. The $P$. alba $\times P$. glandulosa parents were introduced from Korea in 1984. No thinning was applied during the trial period until the time of measurements.

In the spring of 2009 and 2010, 216 trees were sampled from the four sites, so as to retain the consistency of the 5year-old sample. On each site, trees were sampled randomly, six ramets (from the six different trees) per clone were chosen fully at random. Total tree height and diameter at breast height 
Table 1 Location, climatic conditions, and description of five clonal trials

\begin{tabular}{llllllll}
\hline Site & Latitude, ${ }^{\circ} \mathrm{N}$ & Longitude, ${ }^{\circ} \mathrm{W}$ & Mean annual, $\mathrm{T}\left({ }^{\circ} \mathrm{C}\right)$ & Rainfall, mm/year & Planting spacing, $\mathrm{m}$ & Numbers of clones & Sample trees \\
\hline Yanzhou & $33^{\circ} 10^{\prime}$ & $116^{\circ} 49^{\prime}$ & 13.6 & 660 & $2 \times 3$ & 9 & 54 \\
Gaotang & $36^{\circ} 51^{\prime}$ & $116^{\circ} 04^{\prime}$ & 13.1 & 556 & $2 \times 3$ & $2 \times 3$ & 9 \\
Xiangfen & $35^{\circ} 50^{\prime}$ & $111^{\circ} 21^{\prime}$ & 11.5 & 550 & $2 \times 3$ & 9 & 9 \\
Zhengzhou & $34^{\circ} 72^{\prime}$ & $113^{\circ} 97^{\prime}$ & 14.2 & 641 & 54 & 54 \\
\hline
\end{tabular}

(DBH) of all sampled trees were measured at 5 years of age by the triploid poplar breeding program of Beijing Forestry University. Stem volume was calculated for each sample based on a volume function of DBH and tree height used by Chen (1989). For wood chemical composition evaluation, all the tree samples were transported to Beijing Forestry University. A 10-cm-thick disc was taken from each tree at breast height for laboratory measurements.

In the laboratory, the bark and cambium were removed from the stem discs, and the discs with heartwood were cut into small strips used for the determination of chemical composition. Only samples free of compression wood are used in analysis. Wood chips for each disc were composited separately for each tree. Sample discs were chopped, air dried, and ground to wood meal which passed through a 40-mesh sieve. Chemical composition evaluated by the following procedures: ASTM D1105-96 for extractive content, ASTM D1106-96 for Klason lignin content, and GB/T2677 10-1995 (Chinese standard methods for the fibrous raw material) for the holocellulose content (Jin and Kamdem 2009).

\subsection{Statistical analysis}

Analyses of variance were done using the UNIVARIATE procedure of the SPSS software (SPSS for Windows, version 13, SPSS, Chicago, IL). Because of the variance heterogeneity, a

Table 2 Identity and origin of the hybrid clones

\begin{tabular}{|c|c|c|c|}
\hline No. & Clone identity & Parents & Sex \\
\hline 1 & B301 & $(P$. tomentos $a \times P$. bolleana $) \times P$. tomentosa & 우 \\
\hline 2 & B302 & $(P$. tomentos $a \times P$. bolleana $) \times P$. tomentosa & 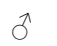 \\
\hline 3 & B303 & $(P$. tomentosa $\times P$. bolleana $) \times P$. tomentosa & 우 \\
\hline 4 & B304 & $(P$. tomentosa $\times P$. bolleana $) \times P$. tomentosa & 우 \\
\hline 5 & B305 & $(P$. tomentosa $\times P$. bolleana $) \times P$. tomentosa & 우 \\
\hline 6 & B306 & $(P$. tomentos $a \times P$. bolleana $) \times P$. tomentosa & q \\
\hline 7 & B312 & $(P$. tomentos $\times \times P$. bolleana $) \times P$. tomentosa & 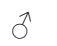 \\
\hline 8 & B330 & $(P$. alba $\times P$. glandulosa $) \times P$. tomentosa & 우 \\
\hline 9 & B331 & $(P$. alba $\times P$. glandulosa $) \times P$. tomentosa & $\hat{\sigma}$ \\
\hline
\end{tabular}

† female, ¿̋ male transformation of the data was done for extractives $\%$ (1/extractives $\%)$, holocellulose $\%(1 /$ holocellulose $\%)$ and lignin $\%$ (1/lignin \%) before analyses of variance were done (Zubizarreta et al. 2007).

Variation among ramets of the sample clones was analyzed by analysis of variance, using a linear model (1) (Zhang et al. 2003):

$X_{i j k}=\mu+C_{i}+L_{j}+C_{i} L_{j}+\varepsilon_{i j k}$

All terms were considered random, except for location considered as a fixed effect.

Repeatability of clone means was calculated according to the following formula:

$R_{c}^{2}=\frac{\widehat{\sigma}_{c}^{2}}{\frac{k 2 \widehat{\sigma}_{c}^{2}}{k 2}+\frac{k 1 \widehat{\sigma}_{L X C}^{2}}{k 2}+\frac{\widehat{\sigma}_{e}^{2}}{k 2}}$

and the individual-tree clonal repeatability across sites was estimated as

$R_{b}{ }^{2}=\widehat{\sigma}_{c}^{2} /\left(\widehat{\sigma}_{c}^{2}+\widehat{\sigma}_{L \times C}^{2}+\widehat{\sigma}_{e}^{2}\right)$

Approximate standard errors (SE) for repeatability estimates were calculated based on the following formula (Becker 1992):

$\operatorname{SE}\left(R_{C}^{2}\right)=\sqrt{\frac{2\left(1-R_{C}^{2}\right)^{2}\left[1+(k 2-1) R_{C}^{2}\right]^{2}}{k 2(k 2-1)(N-1)}}$

where $N$ is the number of clones tested.

The inter-trait clonal correlations on each site were estimated as follows (Becker 1984):

$r_{A(X, Y)}=\frac{\widehat{\sigma}_{C(x, y)}}{\sqrt{\widehat{\sigma}_{C(x)}^{2} \widehat{\sigma}_{C(y)}^{2}}}$

The corresponding clonal variance components were estimated from data collected from the same individual-tree data, using cross-products analogously to using mean squares for estimating variance components. 
The approximate standard errors of genetic correlation estimates were computed using the following equation (Falconer 1981):

$S E=\frac{1-r^{2}}{\sqrt{2}} \sqrt{\frac{\widehat{\sigma}_{\left(R_{X}^{2}\right)} \widehat{\sigma}_{\left(R_{Y}^{2}\right)}}{R_{X}^{2} R_{Y}^{2}}}$

Significance of between-trait genetic correlations was tested approximately using Eq. 4 as the basis for $t$ tests.

The estimates of genetic correlations between the same traits assessed in different sites were calculated to evaluate the contribution of each pair of treatments to the total clone $\times$ environment. These type B genotypic correlations (Burdon 1977) were estimated based on measurements of sample ramets from the same clones planted on different sites using the following formula:

$r_{B(X, Y)}=\frac{r_{P(x 1, y 2)}}{R_{C(x 1)} R_{C(y 2)}}$

The phenotypic correlations of clonal means for each pair of traits were calculated and tested for significance using the
SPSS PROC CORR software and tested for significance using the $F$ test.

\section{Results}

3.1 Basic statistics and variation within and among sites

The mean values, range of variation, and coefficients of phenotypic variation of all studied traits in each of the four clonal trials are presented in Table 3. Trees from the Zhengzhou site had the lowest lignin. The highest lignin was observed at the Gaotang site. The difference of lignin between the lowest and highest means was $7.2 \%$ (Table 3 ). The growth was the fastest at Zhengzhou and slowest at Yanzhou. The highest holocellulose were observed at Gaotang, and the lowest at Yanzhou. Among all sites, the largest stem volumes of trees were found at Zhengzhou. However, phenotypic variation of the composite trait was slightly higher than that of the less productive Yanzhou. Joint analysis of all four trials showed significant site effects for all traits (Table 4). Holocellulose
Table 3 Mean values, ranges of variation, and coefficients of phenotypic variation $\left(\mathrm{CV}_{\mathrm{p}} \%\right)$ of clonal means of growth traits and wood chemical properties at the four sites

$D B H$ diameter at breast height

\begin{tabular}{|c|c|c|c|c|}
\hline \multirow[t]{2}{*}{ Site } & \multirow[t]{2}{*}{ Traits } & \multicolumn{3}{|l|}{ Triploid clones } \\
\hline & & Mean \pm SE & Range (min-max) & $\mathrm{CV}_{\mathrm{p}} \%$ \\
\hline \multirow[t]{6}{*}{ Yanzhou } & Tree height (m) & $12.5 \pm 1.21$ & $10.6-15.4$ & 9.68 \\
\hline & $\mathrm{DBH}(\mathrm{cm})$ & $10.7 \pm 1.01$ & $8.50-13.3$ & 9.44 \\
\hline & Stem volume $\left(\mathrm{m}^{3}\right)$ & $0.0482 \pm 0.0110$ & $0.0262-0.0704$ & 22.9 \\
\hline & Extractives (\%) & $1.72 \pm 0.164$ & $1.43-2.03$ & 9.54 \\
\hline & Holocellulose (\%) & $83.00 \pm 1.05$ & $81.27-85.05$ & 1.27 \\
\hline & Lignin $(\%)$ & $20.24 \pm 0.986$ & $17.88-21.62$ & 4.88 \\
\hline \multirow[t]{6}{*}{ Gaotang } & Tree height (m) & $13.6 \pm 1.21$ & $9.40-16.0$ & 8.90 \\
\hline & $\mathrm{DBH}(\mathrm{cm})$ & $11.6 \pm 1.49$ & $7.80-14.9$ & 12.9 \\
\hline & Stem volume $\left(\mathrm{m}^{3}\right)$ & $0.0618 \pm 0.0184$ & $0.0236-0.1139$ & 29.8 \\
\hline & Extractives $(\%)$ & $2.44 \pm 0.575$ & $1.64-3.74$ & 23.6 \\
\hline & Holocellulose (\%) & $83.73 \pm 0.824$ & $81.85-85.32$ & 0.990 \\
\hline & Lignin (\%) & $20.68 \pm 1.07$ & $19.10-22.49$ & 5.18 \\
\hline \multirow[t]{6}{*}{ Xiangfen } & Tree height (m) & $13.2 \pm 1.11$ & $11.4-15.8$ & 8.41 \\
\hline & $\mathrm{DBH}(\mathrm{cm})$ & $11.7 \pm 1.21$ & $9.00-14.6$ & 10.3 \\
\hline & Stem volume $\left(\mathrm{m}^{3}\right)$ & $0.0608 \pm 0.0156$ & $0.0315-0.1071$ & 25.7 \\
\hline & Extractives (\%) & $2.20 \pm 0.352$ & $1.41-3.13$ & 16.0 \\
\hline & Holocellulose (\%) & $83.32 \pm 0.925$ & $81.59-85.11$ & 1.11 \\
\hline & Lignin $(\%)$ & $19.78 \pm 0.853$ & $18.26-21.22$ & 4.32 \\
\hline \multirow[t]{6}{*}{ Zhengzhou } & Tree height (m) & $13.6 \pm 1.51$ & $9.60-16.6$ & 11.1 \\
\hline & $\mathrm{DBH}(\mathrm{cm})$ & $14.5 \pm 1.46$ & $9.80-17.3$ & 10.1 \\
\hline & Stem volume $\left(\mathrm{m}^{3}\right)$ & $0.0954 \pm 0.0236$ & $0.0335-0.1246$ & 24.7 \\
\hline & Extractives (\%) & $2.05 \pm 0.380$ & $1.48-3.19$ & 18.5 \\
\hline & Holocellulose (\%) & $83.63 \pm 1.18$ & $81.27-85.92$ & 1.41 \\
\hline & Lignin (\%) & $19.29 \pm 0.845$ & $17.71-21.30$ & 4.38 \\
\hline
\end{tabular}


Table 4 Summary of results of analyses of variance and estimated repeatabilities ( \pm standard errors) for tree growth and wood chemical properties at the four sites combined

\begin{tabular}{|c|c|c|c|c|c|c|}
\hline \multirow[t]{2}{*}{ Trait } & \multicolumn{3}{|l|}{$P$ value } & \multirow[t]{2}{*}{$R_{b}^{2}$} & \multirow[t]{2}{*}{$R_{c}{ }^{2}$} & \multirow[t]{2}{*}{$\%$} \\
\hline & Clones & Sites & Sites $\times$ clones & & & \\
\hline Tree height & 0.002 & 0.006 & $<0.001$ & $0.232 \pm 0.104$ & $0.771 \pm 0.0913$ & 56.5 \\
\hline DBH & 0.011 & $<0.001$ & 0.001 & $0.152 \pm 0.0811$ & $0.696 \pm 0.0706$ & 50.6 \\
\hline Stem volume & 0.027 & $<0.001$ & $<0.001$ & $0.144 \pm 0.0786$ & $0.633 \pm 0.859$ & 40.5 \\
\hline Extractives & 0.001 & $<0.001$ & 0.041 & $0.315 \pm 0.133$ & $0.799 \pm 0.0856$ & 65.3 \\
\hline Holocellulose & 0.019 & 0.030 & 0.561 & $0.146 \pm 0.0968$ & $0.659 \pm 0.117$ & 41.4 \\
\hline Lignin & $<0.001$ & 0.001 & 0.006 & $0.357 \pm 0.108$ & $0.811 \pm 0.0816$ & 66.2 \\
\hline
\end{tabular}

$\%$ estimated ratio of clonal variance to the sum of clonal plus clone $\times$ site variances, $D B H$ diameter at breast height

and lignin except for extractives and stem volume displayed a small phenotypic variation $(\mathrm{CV}=0.990-5.18 \%$ ), which was much lower than tree height variation and $\mathrm{DBH}$ variation.

\subsection{Clonal variation and repeatability}

Results of analysis of variance for the four sites combined are summarized in Table 4. Significant differences in both growth traits and wood chemical properties were found among the clones (Table 4). For all traits, variance due to error (namely, differences among ramets within a clone within a site) accounted for most of the variation in these traits, ranging from 46.1 to $64.5 \%$ of the total variation. Most of the variance in lignin (35.6\%), however, was due to the clone. Therefore, lignin in the triploid hybrid poplar clones had the highest estimated repeatability $(0.811)$ and estimated individual-tree clonal repeatability (0.357) (Table 4).

Estimates of repeatability at clone-mean and individualtree levels for tree growth and chemical properties of wood at individual sites are presented in Table 5. No significant difference in tree height, DBH, stem volume, extractives, and holocellulose was found among the clones at Yanzhou. Therefore, we did not estimate the repeatabilities of these traits. Estimated clonal repeatability for lignin ranged from 0.726 to 0.906 and from 0.758 to 0.919 for extractives. Estimated clonal repeatability of growth traits varied from 0.614 to 0.908 . However, these differences in repeatability estimates were often insignificant. Repeatability of DBH ranged from 0.614 to 0.823 , which was as much as that of stem volume (0.699 to 0.818$)$.

Table 5 Analysis of variance results and estimated repeatabilities for tree growth and wood chemical properties at each site

\begin{tabular}{|c|c|c|c|c|c|c|}
\hline \multirow[t]{2}{*}{ Sites } & \multicolumn{6}{|l|}{ Traits } \\
\hline & Tree height & $\mathrm{DBH}$ & Stem volume & Extractives & Holocellulose & Lignin \\
\hline \multicolumn{7}{|l|}{ Yanzhou } \\
\hline$P$ value & 0.389 & 0.516 & 0.786 & 0.355 & 0.760 & $<0.001$ \\
\hline$R_{b}^{2}$ & - & - & - & - & - & 0.763 \\
\hline$R_{c}{ }^{2}$ & - & - & - & - & - & $0.906 \pm 0.0539$ \\
\hline \multicolumn{7}{|l|}{ Gaotang } \\
\hline$P$ value & $<0.001$ & $<0.001$ & $<0.001$ & $<0.001$ & 0.006 & 0.165 \\
\hline$R_{b}^{2}$ & 0.447 & 0.436 & 0.425 & 0.781 & 0.658 & - \\
\hline$R_{c}^{2}$ & $0.829 \pm 0.0803$ & $0.823 \pm 0.0826$ & $0.820 \pm 0.0838$ & $0.919 \pm 0.0469$ & $0.761 \pm 0.02$ & - \\
\hline \multicolumn{7}{|l|}{ Xiangfen } \\
\hline$P$ value & $<0.001$ & 0.020 & 0.005 & 0.321 & 0.767 & 0.010 \\
\hline$R_{b}^{2}$ & 0.390 & 0.209 & 0.294 & - & - & 0.477 \\
\hline$R_{c}^{2}$ & $0.794 \pm 0.0935$ & $0.614 \pm 0.143$ & $0.699 \pm 0.123$ & - & - & $0.726 \pm 0.137$ \\
\hline \multicolumn{7}{|l|}{ Zhengzhou } \\
\hline$P$ value & $<0.001$ & 0.001 & $<0.001$ & 0.006 & 0.106 & $<0.001$ \\
\hline$R_{b}^{2}$ & 0.623 & 0.354 & 0.434 & 0.511 & - & 0.751 \\
\hline$R_{c}^{2}$ & $0.908 \pm 0.0465$ & $0.767 \pm 0.102$ & $0.818 \pm 0.0845$ & $0.758 \pm 0.124$ & - & $0.901 \pm 0.0498$ \\
\hline
\end{tabular}

$D B H$ diameter at breast height 


\subsection{Genotype by environment interaction}

In this study, significant interaction of clone $\times$ site was observed for the studies of all chemical properties of wood (except for holocellulose) and tree growth traits (Table 4). Holocellulose had a higher ratio of clone $\times$ site interaction variance to the sum of clonal and clone $\times$ site interaction variances $(66.6 \%)$ than other traits.

Inter-site genetic correlations are presented in Table 6. Some inter-site genetic correlations between the same traits with pairs of Yanzhou-Gaotang, Yanzhou-Xiangfen, and Yanzhou-Zhengzhou were not estimated because no significant difference in tree height, DBH, stem volume, extractives, and holocellulose was found among the clones at Yanzhou. Most of the inter-site ( $\mathrm{B}$ type) genetic correlations between the same traits with pairs of sites were either moderate or strong (Table 6). Higher inter-site genetic correlations were observed in chemical properties of wood (except for holocellulose and lignin) than growth traits. Among all studied traits, extractives showed the highest inter-site genetic correlations (0.901), followed by correlations in lignin (0.392-0.794). However, compared with chemical properties of wood, growth traits had generally lower inter-site genetic correlations (0.313-0.778). The lowest inter-site genetic correlations were observed in stem volume; this could be due to the lower estimated ratio of clonal variance to the sum of clonal and clone $\times$ site variances (Table 4).

\subsection{Genetic correlations between traits}

Estimated genetic correlations and phenotypic correlations between chemical properties of wood and growth traits are presented in Table 7. Most of the genetic correlations between chemical properties of wood and growth traits were not estimated at Yanzhou due to the absence of repeatabilities of tree height, DBH, stem volume, extractives, and holocellulose. Those between chemical properties of wood and growth traits were not significantly correlated with both phenotypically and genetically. However, a weak and negative estimated correlation between lignin and growth traits existed. Among chemical properties of wood, a positive or significantly positive estimated genetic correlation was found between lignin and extractives at each site. However, a significantly negative estimated genetic correlation between holocellulose and extractives was observed at each site. A negative estimated correlation was also observed between lignin and holocellulose. There are some strong positive autocorrelations among stem volume, tree height, and DBH, because stem volume was derived from tree height and DBH.

\section{Discussion}

\subsection{Variation among sites}

Site effects reflect the reaction of trees to the combined effects of edaphic as well as local and regional climatic conditions (Pliura et al. 2007). Even if present experiments were not designed to separate these various effects, some conclusions could be drawn. The slower growth rate at Yanzhou was probably due to poor drainage (because of soil compaction) and wet weather during the early period of the trial (Zhang et al. 2012). The joint analysis of all the four trials showed significant site effects for all studied traits (Table 4). Site effects were much smaller for holocellulose, as evidenced by larger $P$ values, indicating that trees had less phenotypic plasticity for this character.

The mean lignin of all studied clones was lower at the most productive Zhengzhou site than the least productive Yanzhou site (Table 3). This tendency corresponds to the expectation that plants grow at the optimum conditions with lower lignin, as lignin is negatively correlated with tree growth, which in turn relates to plant nutritional status (Yu et al. 2001).

\subsection{Clonal variation and repeatability}

Clonal effects in the joint analysis for all chemical properties of wood and growth traits were significant $(P<0.05)$. The higher significance of clonal effects was observed at Gaotang,

Table 6 Estimated inter-site genetic correlations (with approximate standard errors in brackets) for the growth traits and wood chemical properties

\begin{tabular}{|c|c|c|c|c|c|c|}
\hline Sites & Tree height & $\mathrm{DBH}$ & Stem volume & Extractives & Holocellulose & Lignin \\
\hline Yanzhou-Gaotang & - & - & - & - & - & - \\
\hline Yanzhou-Xiangfen & - & - & - & - & - & $0.794 *(0.0367)$ \\
\hline Yanzhou-Zhengzhou & - & - & - & - & - & $0.392(0.0343)$ \\
\hline Gaotang-Xiangfen & $0.689 *(0.0397)$ & $0.566(0.0735)$ & $0.511(0.0701)$ & - & - & - \\
\hline Gaotang-Zhengzhou & $0.571(0.0336)$ & $0.498(0.0622)$ & $0.313(0.0655)$ & $0.901(0.0122)$ & - & - \\
\hline Xiangfen-Zhengzhou & $0.776 *(0.0118)$ & $0.778 *(0.0491)$ & $0.763 *(0.0398)$ & - & - & $0.589(0.0472)$ \\
\hline
\end{tabular}

$D B H$ diameter at breast height

$* P<0.05$, significant correlations 
Table 7 Estimated inter-trait genetic correlations (above the diagonal) and phenotypic correlations (below the diagonal) between growth traits and wood chemical properties across the four sites
$D B H$ diameter at breast height

${ }^{*} P<0.05$, significant correlations; $* * P<0.01$

\begin{tabular}{|c|c|c|c|c|c|c|}
\hline Trait & Tree height & $\mathrm{DBH}$ & Stem volume & Extractives & Holocellulose & Lignin \\
\hline \multicolumn{7}{|l|}{ Yanzhou } \\
\hline Tree height & & - & - & - & - & - \\
\hline $\mathrm{DBH}$ & 0.244 & & - & - & - & - \\
\hline Stem volume & $0.742 *$ & $0.903^{* *}$ & & & & \\
\hline Extractives & 0.281 & 0.552 & 0.603 & & - & - \\
\hline Holocellulose & 0.012 & -0.535 & -0.452 & $-0.726^{*}$ & & - \\
\hline Lignin & -0.058 & -0.100 & -0.216 & 0.347 & -0.658 & \\
\hline \multicolumn{7}{|l|}{ Gaotang } \\
\hline Tree height & & $0.820^{*}$ & $0.931 *$ & 0.00573 & 0.0126 & - \\
\hline $\mathrm{DBH}$ & $0.677^{*}$ & & $1.19 * *$ & 0.477 & -0.488 & - \\
\hline Stem volume & $0.768^{*}$ & $0.981 * *$ & & 0.372 & -0.392 & - \\
\hline Extractives & 0.005 & 0.415 & 0.323 & & $-0.928 *$ & - \\
\hline Holocellulose & 0.0100 & -0.386 & -0.310 & $-0.776^{*}$ & & - \\
\hline Lignin & -0.033 & -0.155 & -0.110 & 0.038 & -0.324 & \\
\hline \multicolumn{7}{|l|}{ Xiangfen } \\
\hline Tree height & & $1.37 * *$ & $1.31 * *$ & - & - & -0.572 \\
\hline DBH & $0.950 * *$ & & $1.51^{* *}$ & - & - & -0.778 \\
\hline Stem volume & $0.978^{* *}$ & $0.989 * *$ & & - & - & -0.674 \\
\hline Extractives & 0.402 & 0.358 & 0.377 & & - & - \\
\hline Holocellulose & -0.518 & -0.409 & -0.416 & $-0.727^{*}$ & & - \\
\hline Lignin & -0.434 & -0.516 & -0.480 & 0.107 & -0.141 & \\
\hline \multicolumn{7}{|l|}{ Zhengzhou } \\
\hline Tree height & & $0.956^{*}$ & $1.08 * *$ & 0.0445 & - & -0.075 \\
\hline $\mathrm{DBH}$ & $0.795^{*}$ & & $1.21 * *$ & 0.0131 & - & -0.118 \\
\hline Stem volume & $0.927 * *$ & $0.958 * *$ & & 0.00635 & - & -0.0711 \\
\hline Extractives & 0.0370 & 0.0100 & 0.00500 & & - & $0.923 *$ \\
\hline Holocellulose & 0.056 & 0.163 & 0.0960 & $-0.836^{*}$ & & - \\
\hline Lignin & -0.067 & -0.0981 & -0.0610 & $0.763^{*}$ & $-0.904 * *$ & \\
\hline
\end{tabular}

Xiangfen, and Zhengzhou sites (except for holocellulose) (Table 5), indicating that these three sites resulted in larger genetic variation and smaller environment variation than a less productive site. Previous studies (Yanchuk et al. 1983; Yu et al. 2001; Zhang et al. 2003, 2012; Li et al. 2005; Seyed et al. 2011) also reported a significant clonal effect in wood properties and growth traits of poplars or their hybrids. Same difference was found in the same clones, or clones or hybrids are not important, for example, Yanchuk et al. (1983), who studied in Alberta.

From tree breeding and wood utilization perspectives for pulp and paper, the variation in lignin content among triploid hybrids was substantial, with a phenotypic CV of $4.32-5.18 \%$, depending on the site. The lignin values of triploid poplar hybrids, which varied from 17.71 to $22.49 \%$, were similar to those reported previously for clones of $P . \times$ euramericana (Dode) Guinier (Luo and Polle 2009), Populus nigra L. and P. alba L. (Kačík et al. 2012), and P. tomentosa (Ren and Zhou 2006), for hybrids involving Populus tremula and P. alba (Lapierre et al. 1999). However, the present lignin values of triploid clones were somewhat lower than those reported for Populus ciliata Wall ex Royle (Khattak and Ghazi 2001). Higher mean lignin values also had been reported for clones of Populus trichocarpa Torr. (Studer et al. 2011), for hybrid poplars (Sannigrahi et al. 2010). These differences might be due to the methods of estimation of lignin, the parentage of hybrids involved in the studies (e.g., P. tremula), clonal variation within hybrids, differences in environmental conditions, differences in cambial age of sampled and measured rings, and differences in sampling height.

The mean holocellulose of individual clones ranged from 81.27 to $85.05 \%$ at Yanzhou, from 81.85 to $85.32 \%$ at Gaotang, from 81.59 to $85.11 \%$ at Xiangfen, and from 81.27 to 85.92 at Zhengzhou. Jin and Kamdem (2009) reported that holocellulose of 6-year-old diploid $P$. nigra hybrids ranged from 80.05 to $80.18 \%$. Fengel and Wegener (2003) summarized the results of several authors and presented the following data of various poplar clones: holocellulose 78.4 $80.3 \%$, lignin 17.6-20.9\%, extractives 3.3-3.8\%, and ash $0.4 \%$. Ren and Zhou reported (2006) that holocellulose of $P$. 
$\times$ canadensis Moench cv. I-214 was $80.43 \%$. Olson et al. (1985) reported that the average holocellulose of 75 3-yearold Populus deltoides ssp. clones was of $80.2 \%$. Khattak and Ghazi (2001) found that average holocellulose of $P$. ciliata Maximowiczii clones was $69.10 \%$. Obviously, in the present study, the mean holocellulose $(83.00-83.73 \%)$ of triploid clones measured was slightly higher than that of the other diploid hybrids. The higher holocellulose might be partly due to the fact that triploid breeding of $P$. tomentosa can improve the holocellulose (Zhu 2006).

\subsection{Genotype by site interaction}

As poplar breeding programs dealt with developing clones suitable for different environments, genotype $\times$ site interaction might have significant impact on accuracy of breeding values, thus reducing genetic gain. With incongruence between test locations and deployment zones, $\mathrm{G} \times \mathrm{E}$ interaction, if improperly accounted for, could result in bias of estimates and thus a decrease of genetic gain. Significant clone $\times$ site interaction for lignin and extractives was observed (Table 4). This finding agreed with previous reports on the presence of significant clone $\times$ site interaction for lignin and extractives of poplar hybrid clones (Yu et al. 2001; Kačík et al. 2012). To reduce the cost, chemical properties were, in previous studies, not measured for each clone at each site on hybrid poplar clones. Clone $\times$ site interaction observed in the current study might have a certain limit because of the wide array of site differences. For growth traits, clone $\times$ site interaction in the present study, while significant, might be sufficient to justify detailed clonal testing in order to achieve optimal clonal deployment.

Theoretically, type B genetic correlations range between 0.0 and 1.0. High correlation coefficients show lack of genotype by environment interactions. The type $\mathrm{B}$ genetic correlation value (0.392) between Yanzhou and Zhengzhou for lignin (Table 6) indicated that true $\mathrm{G} \times \mathrm{E}$ interaction was present and that difference between these two sites contributed the most to the clone $\times$ site interaction. However, the estimated type B genotypic correlation between Gaotang and Zhengzhou for extractives was mostly positive (Table 6), which indicated that the chemical property of wood of the clones was rather stable across sites. This observation corresponded to the conclusions of Zobel and Jett (1995) that relative performance of genotypes across environments for wood properties was rather stable.

\subsection{Genetic correlations}

Earlier studies of hybrid aspen clones suggested that lignin had a negative association with volume growth (Yu et al. 2001). In the present study, a negative genetic correlation was also observed between lignin and stem volume. Therefore, selection for SV might lead to a slight decrease in lignin.
Lignin had moderately high and negative (favorable) genetic correlations with holocellulose. The favorable correlations indicated that selection for holocellulose could decrease lignin in a selection program of triploid hybrid clones of $P$. tomentosa. Increasing holocellulose may result in the production of more paper per cubic meter of wood, less lignin, and more efficient pulping and bleaching. However, before considering one or two wood traits for breeding and selection, more efforts are needed. Tree improvement programs should decide which traits will be of most importance in the future before incorporating them into their breeding programs.

\section{Conclusion}

From the tests and the analyses conducted, it can be appeared to be that chemical properties of wood (except for holocellulose and extractives) of trees were under stronger genetic control than growth traits. Individual-tree repeatabilities were generally weak, but repeatabilities of clonal means were from moderate to high. The site/location had a highly significant $(P<0.001)$ effect on extractives and tree growth and a moderate effect on lignin and holocellulose. Clonal effects were also significant $(P<0.05)$ for all studied traits. Clone $\times$ site interactions were significant for all studied traits except for holocellulose. No significant estimated correlations between chemical properties of wood and growth traits were observed. However, a weak and negative estimated correlation between lignin and growth traits existed. This suggests that selection for growth traits might lead to a minor reduction in lignin in triploid breeding of $P$. tomentosa. The results from this study were based on a small number of triploid hybrid clones derived from several parents. Further research is needed to fully understand the implications of the genetic control of wood chemical properties and their potential for inclusion in tree improvement programs.

Acknowledgments This study was mainly supported by the $12^{\text {th }} \mathrm{Na}$ tional Key Technology R\&D Program (NO. 2012BAD01B0302) and the National Natural Science Foundation of China (No. 31370659). The authors would like to thank Dr. Jicheng Pei from Tianjin University of Science \& Technology for his assistance with wood chemical properties measurements.

\section{References}

Becker WA (1984) Manual of quantitative genetics. Academic Enterprices, Pullman, Washington, DC, p 190

Becker WA (1992) Manual of quantitative genetics. Academic Enterprises, Pullman, p 160

Burdon RD (1977) Genetic correlation as a concept for studying genotype $\times$ environment interaction in forest tree breeding. Silvae Genet 26:168-175 
Chen ZS (1989) The establishment of binomial stock volume tables of poplar. J For Res 2:78-83

Falconer DS (1981) Introduction to quantitative genetics, 3rd edn. Longman, London, pp 285-286

Fengel D, Wegener G (2003) Wood: chemistry, ultrastructure, reactions. Verlag Kessel, München, Germany, pp 26-65

Hannrup B, Ekberg I (1998) Age-age correlations for tracheid length and wood density in Pinus sylvestris. Can J For Res 28:1373-1379

Hylen G (1999) Age trends in genetic parameters of wood density in young Norway spruce. Can J For Res 29:135-143

Jin XZ, Kamdem DP (2009) Chemical composition, crystallinity and crystallite cellulose size in Populus hybrids and aspen. Cellulose Chem Technol 43:229-234

Kačík F, Ďurkovič J, Kačíková D (2012) Chemical profiles of wood components of poplar clones for their energy utilization. Energies 5:5243-5256

Kang XY, Zhu ZT, Lin HB (1999) Study on the effective treating period for pollen chromosome doubling of $P$. tomentosa $\times P$. bolleana. Sci Silvae Sinicae 35:21-24

Kang XY, Zhu ZT, Lin HB (2000) Radiosensitivity of different ploidy pollen in poplar and its application. Acta Genet Sin 27:78-82

Khattak TM, Ghazi J (2001) Suitability of some non-commercial fast growing wood yielding trees growing in Azad Kashmir for the production of pulp and paper. Pak J Bot 33:729-732

Lapierre C, Pollet B, Petit-Conil M, Toval G, Romero J, Pilate G, Leplé JC, Boerjan W, Ferret V, Denadai V et al (1999) Structural alterations of lignins in transgenic poplars with depressed cinnamyl alcohol dehydrogenase or caffeic acid O-methyltransferase activity have an opposite impact on the efficiency of industrial kraft pulping. Plant Physiol 119:153-163

Li SW, Jiang YZ, Wang GY, Wang WD, Qiao YL (2005) Joint selection for growth and wood properties in Aigeiros clones. Sci Silvae Sinicae 41:53-58

Lindström H, Harris P, Sorensson CT, Evans R (2004) Stiffness and wood variation of 3-year old Pinus radiata clones. Wood Sci Technol 38: 579-597

Luo Z, Polle A (2009) Wood composition and energy content in a poplar short rotation plantation on fertilized agricultural land in a future $\mathrm{CO}_{2}$ atmosphere. Global Change Biol 15:38-47

Naranjo SS, Moya R, Chauhan S, Moya R (2012) Early genetic evaluation of morphology and some wood properties of Tectona grandis $\mathrm{L}$. clones. Silvae Genet 61:58-65

Olson JR, Jourdain CR, Rousseau RJ (1985) Selection for cellulose content, specific gravity and volume in young Populus deltoids clones. Can J For Res 15:393-396

Pliura A, Zhang SY, Mackay J, Bousquet J (2007) Genotypic variation in wood density and growth traits of poplar hybrids at four clonal trials. For Ecol Manag 238:92-106

Pu JW, Song JL, Rao CL (2002) Studies on variations of chemical components of triploid clones in Populus tomentosa Carr. Paper Sci Technol 21:1-4

Ren HQ, Zhou HB (2006) Analysis on chemical components and fiber dimensions of triploid Populus tomentosa. J Anhui Agric Univ 33: $160-163$
Sannigrahi P, Ragauskas AJ, Tuskan GA (2010) Poplar as a feedstock for biofuels: a review of compositional characteristics. Biofuels Bioprod Bioref 4:209-226

Seyed MS, Mohsen FK, Seyed AS (2011) Genetic variability of some morphological traits in poplar clones. Am J Sci Res 13:113-117

Shupe TF, Choong ET, Yang CH (1996) The effects of silvicultural treatments on the chemical composition of plantation-grown loblolly pine wood. Wood Fiber Sci 28:295-300

Studer MH, DeMartini JD, Davis MF, Sykes RW, Davison B, Keller M, Tuskan GA, Wyman CE (2011) Lignin content in natural Populus variants affects sugar release. Proc Natl Acad Sci U S A 108:6300 6305

Sykes R, Isik F, Li B, Kadla J, Chang HM (2003) Genetic variation of juvenile wood properties in a loblolly pine progeny test. TAPPI J 2:3-8

Wu F, Zhang PD, Pei JC, Kang XY (2011) Genetic variation of fiber properties of triploid Chinese white poplar planted in Beijing. J Northeast For Univ 39:4-7

Wu F, Zhang PD, Pei JC, Kang XY (2013) Genotypic parameters of wood density and fiber traits in triploid hybrid clones of Populus tomentosa at five clonal trials. Ann For Sci 70:751-759

Wu F, Zhang PD, Pei JC, Kang XY (2014) Within-stem variation in wood properties of triploid hybrids of Populus tomentosa at three clonal trials. Scand J For Res 29:71-76

Xing XT, Zhang ZY (2000) Genetic variation in wood density of triploid clones of Populus tomentosa. J Beijing For Univ 22:16-20

Yanchuk AD, Dancik BP, Micko MM (1983) Intraclonal variation in wood density of trembling aspen in Alberta. Wood Fiber Sci 15: 387-394

Yao CL, Pu JW (1998) Timber characteristics and pulp properties of the triploid clones of Populus tomentosa. J Beijing For Univ 20:18-21

Yu Q, Pulkkinen P, Rautio M, Haapanen M, Alen R, Stener LG, Beuker E, Tigerstedt PMA (2001) Genetic control of wood physiochemical properties, growth and phenology in hybrid aspen clones. Can J For Res 31:1348-1356

Zhang SY, Yu Q, Chauret G, Koubaa A (2003) Selection for both growth and wood properties in hybrid poplar clones. For Sci 49:901-908

Zhang PD, Wu F, Kang XY (2012) Genotypic variation in wood properties and growth traits of triploid hybrid clones of Populus tomentosa at three clonal trials. Tree Genet Genom 8:1041-1050

Zhang PD, Wu F, Kang XY (2013) Genetic control of fiber properties and growth in triploid hybrid clones of Populus tomentosa. Scand J For Res 28:621-630

Zhu ZT (2006) Genetic improvement of Populus tomentosa. Chinese Forestry Press, Beijing, China, pp 155-220

Zhu ZT, Lin HB, Kang XY (1995) Studies on allotriploid breeding of Populus tomentosa B301 clones. Sci Silvae Sinicae 31:499-505

Zobel B (1989) Wood variation, its causes and control. Springer, Berlin, p 363

Zobel BJ, Jett JB (1995) Genetics of wood production. Springer, Berlin Heidelberg, Germany, p337

Zubizarreta GA, Peltola H, Pulkkinen P, Jaantinen R, Pappinen A, Kellomäki S (2007) Differences in growth and wood property traits in cloned Norway spruce (Picea abies). Can J For Res 37:2600 2611 